\title{
Original
}

\section{Globin-intron Sequences Imply Molecular Relationships Between the Galapagos Giant Tortoise and the Aldabra Giant Tortoise}

\author{
Fumio SHISHIKURA \\ Laboratory for Electron Beam Research and Application (LEBRA), Nihon University
}

\begin{abstract}
The author previously established a molecular tree based on the cDNA-derived primary structures of globins in two giant tortoises, Geochelone nigra and G. gigantea. The divergence time was estimated to be 15-21 million years ago. In the present study, the author reexamined the divergence time of these two species using another source of genetic information-globin-introns-including those from the Chaco tortoise (G. chilensis), a close relative of G. nigra. The previously determined divergence time was supported by the findings of this intron study. However, the inter-relationships based on the intron nucleotide sequences of the globins from the three Geochelone species remain controversial, because it is difficult to determine which of the three is the ancestral species. In addition, the nucleotide sequences reveal the following interesting characteristics: (1) an abnormal GC dinucleotide sequence located at the 5'-splicing site of the second intron of $\alpha^{\mathrm{D}}$ globins instead of a consensus GT-this finding is common to all studied Geochelone species; (2) a repeated sequence 5'-GCCCCGCGCCCCGC-3' found only in the first intron of the G. nigra $\alpha^{\mathrm{A}}$ globin gene, is a unique feature distinguishing the Galapagos giant tortoise from the other Geochelone tortoises that have non-repeated GCCCCGC sequences.
\end{abstract}

Key wards: Aldabra giant tortoise, Chaco tortoise, Galapagos giant tortoise, globin intron, molecular relationship

アルダブラゾウガメ , チャコリクガメ , ガラパゴスゾウガメ , グロビンイントロン , 分 子系統関係

(J. Nihon Univ. Med. Ass., 2013; 72 (6): 326-334)

\section{Introduction}

Only two species of giant tortoise are currently known: the Galapagos giant tortoise (Geochelone nigra; synonym: Chelonoidis nigra) and the Aldabra giant tortoise (Geochelone gigantea; synonym: Dipsochelys dussumieri), whose present habitats are restricted to oceanic islands, one being volcanic, Galapagos Archipelago ${ }^{1,2)}$ and the other being an atoll, Aldabra Atoll in the Seychelles ${ }^{3,4)}$. The Galapagos Archipelago, consisting of 13 main islands, emerged about 5 to 9 million years ago (mya) ${ }^{2}$. In contrast, the most recent emergence of the Aldabra Atoll occurred only 13,000 years before the present day to form a configuration of four main islands ${ }^{3)}$. Here, the author aims to provide scientific information on the origin and the divergence time of the two giant tortoise species, including a close relative to the Galapagos giant tortoises, the Chaco tortoise (Geochelone chilensis; synonym: Chelonoidis chilensis). To analyze intra-genus relationships, the author first constructed a molecular tree based on the primary structure of the globin subunits $\alpha^{\mathrm{A}}, \alpha^{\mathrm{D}}$, and $\beta^{5-7)}$. Both giant tortoise species were shown to diverge around 15-21 mya ${ }^{6,7)}$, which represents a significant delay following the break-up of Gondwana, which separated into Africa and South America during the Cretaceous period 65-135 mya ${ }^{8,9)}$. Hence, the author provides genetic relationships, in particular divergence times of the three Geochelone species, based on globin genealogy.

Globin genes consist of three exons and two introns, and exon nucleotide sequences (or primary structures) were widely used for construction of molecular relationships among living organisms ${ }^{10-13)}$. On the contrary, very little is known about intron nucleotide sequences of reptilian globin ${ }^{6}$. The author reports all intron nucleotide sequences of the globin genes, including $\alpha^{\mathrm{A}}, \alpha^{\mathrm{D}}$, and $\beta$ in the above three species, and provides the following two molecular trees: 1) a tree based on a complete sequence of the two introns and three exons compared with a tree based on only the three exons (a protein coding sequence); 2) a tree based on only intron nucleotide sequences. The author also reveals the following two interesting structural characteristics of the introns: 1) an abnormal GC dinucleotide sequence at the 5 '-splicing (donor) site of the second intron of the $\alpha^{\mathrm{D}}$ globin instead of a consensus GT dinucleotide sequence, whose abnormal sequence was found at the 5'-splicing site in all of the

Received: October 15, Accepted: October 31, 2013 


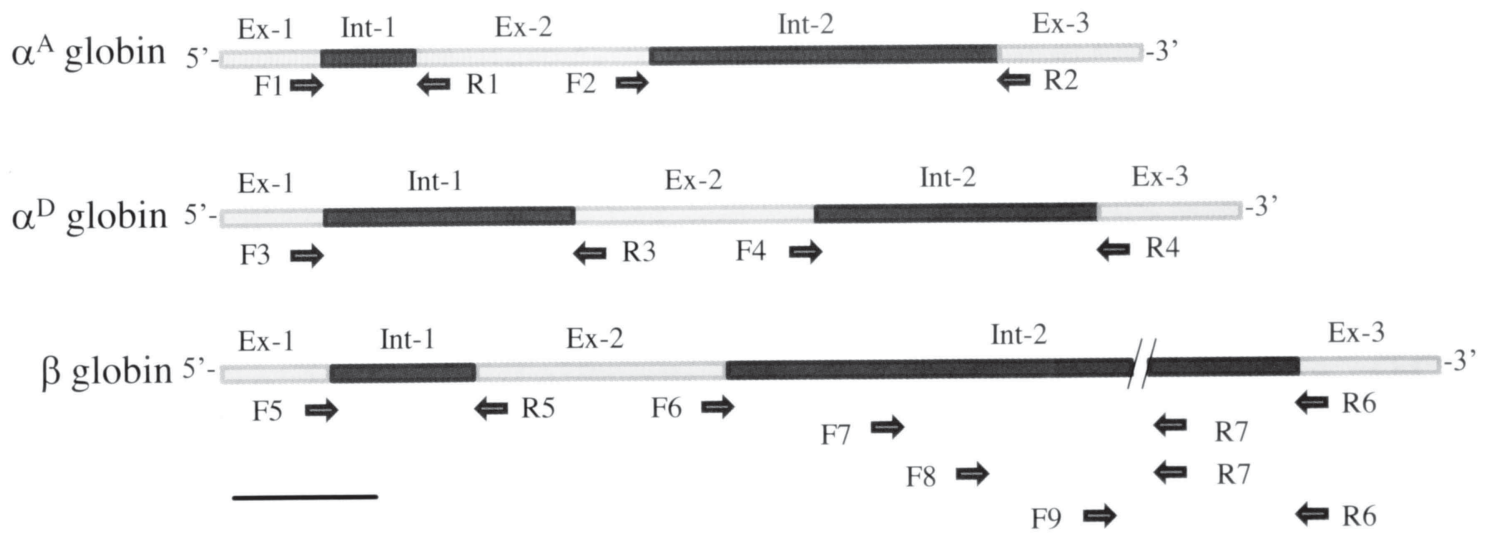

Fig. 1 Intron sequence analysis strategy Refer to Table 1 for nucleotide sequences of the primers (F1-F9, R1-R6). Bar: 120 base pairs.

Table 1 Oligonucleotide primers used in PCR globin-intron amplification

\begin{tabular}{clrl}
\hline Primer Nucleotide sequence & \multicolumn{2}{c}{ Primer Nucleotide sequence } \\
\hline F1 & M13F-gamtatggctccgagaccctgg & R1 & M13R-tggtggaggggtagacgaygaac \\
F2 & M13F-tgcgcgtggayccygtcaacttc & R2 & M13R-accaccacgaagcacaggttcag \\
F3 & M13F-gacttggggccgaggccctgg & R3 & M13R-tggtggaggggtagacgrtgaac \\
F4 & M13F-tgcgcgtggacccggtcaacttc & R4 & M13R-accacctggaagcwgtgggacag \\
F5 & M13F-gargtkggtggcgaagccctggc & R5 & M13R-gtggtccaggggtagacgatcag \\
F6 & M13F-tgcatgtggatccygagaacttc & R6 & M13R-acgatgatgaggatttgcccag \\
F7 & M13F-ayacatgcrggaagggactaaac & R7 & M13R-ctccgtgaggttcttagcctcag \\
F8 & M13F-ggagtggcagcaaaagcctcawg & & \\
F9 & M13F-ccaggcatgacggtgagtggctg & & \\
\hline
\end{tabular}

M13F=GTAAAACGACGGCCAGT; M13R=CAGGAAACAGCTATGAC;

$\mathrm{r}=\mathrm{a}$ or $\mathrm{g}, \mathrm{y}=\mathrm{c}$ or $\mathrm{t}, \mathrm{w}=\mathrm{a}$ or $\mathrm{t}$

second introns of the $\alpha^{\mathrm{D}}$ globins from all three Geochelone species; and 2) a GCCCCGCGCCCCGC repeat found in the first intron of the G. nigra $\alpha^{\mathrm{A}}$ globin gene, which provides a practical criterion for judging the evolutionary differences between Geochelone species. Finally, the author provides a scenario concerning colonization of the Galapagos Archipelago and the Aldabra Atoll by the respective tortoise species.

\section{Materials and Methods}

\section{Geochelone species}

The Galapagos giant tortoise is the largest species of tortoises, whose habitat is restricted to the Galapagos Archipelago, which comprises volcanic islands about $1000 \mathrm{~km}$ west of Ecuador. The author used a specimen from Ueno Zoological Garden (Tokyo, Japan), which is recorded as being a donation from the late Dr. Koichi Sekiguchi (former Professor Emeritus at Tsukuba University). The Aldabra tortoise is the other extant giant tortoise, whose present habitat, the Aldabra Atoll, is located about $640 \mathrm{~km}$ from East Africa's coast and about $420 \mathrm{~km}$ from the northern tip of Madagascar. Aldabra tortoise specimens used in the present study were obtained from Osaka Municipal Tennoji Zoo (Osaka, Japan). The third, the Chaco or
Argentine tortoise, is the smallest species of land tortoises, despite been regarded as a close relative to the Galapagos giant tortoise ${ }^{14)}$.

\section{Preparation of genomic DNA}

For preparation of genomic DNAs from $100 \%$ ethanol-fixed red blood cells of adult giant tortoises and the Chaco tortoises, DNA samples were prepared as described previously ${ }^{6,7)}$ and stored at $-80^{\circ} \mathrm{C}$.

\section{Primer design and PCR conditions}

Strategies for the PCR amplification of intron fragments and the design of degenerated primers are shown in Fig. 1 and Table 1, respectively. Before sequencing the PCR amplified fragments with a BigDye Terminator v. 1.1 Cycle Sequencing Kit (Applied Biosystems, Foster City, CA), the degenerate oligonucleotide primers were tailed with the pUC/M13 forward or $\mathrm{pUC} / \mathrm{M} 13$ reverse sequencing primer tail (forward 17-mer: 5'-GTAAAACGACGGCCAGT-3', Sigma-Aldrich; and reverse 17-mer: 5'-CAGGAAA CAGCTATGAC-3', Promega, Tokyo, Japan). PCR amplification and the thermal profile including denaturation of the first 5 cycles were described in the previous reports ${ }^{6,7)}$. 
Extraction of DNA fragments, and cycle sequencing

Agarose gel (1.5\%) was used to examine the purity and the size range of the PCR products amplified from the genomic DNA. The gel slices $(<500 \mu \mathrm{g})$ containing the PCR products were placed into the GenElute Agarose Spin column (Sigma-Aldrich) and centrifuged for $10 \mathrm{~min}$ at $14,000 \times \mathrm{g}$. The filtrate was concentrated using a Microcon-100 (Millipore Corp., Bedford, MA) and sequenced with an ABI PRISM BigDye Terminator Cycle Sequencing Ready Reaction Kit (Applied Biosystems).

Using Centri-Sep spin columns (Princeton Separations P/N CS-900, Tokyo, Japan) for the removal of unincorporated dye terminations, the samples were analyzed on an ABI PRISM 310 Genetic Analyzer (Life Technologies Japan, Tokyo, Japan) as well as on an ABI 3130 Genetic Analyzer (Life Technologies).

\section{Computer analysis}

A multiple alignment program, Clustal X v. $1.81^{15)}$ or Clustal W v. 2.1 ${ }^{16)}$ was used to align separately the first introns of the $\alpha^{\mathrm{A}}$ globins and the second introns of the $\alpha^{\mathrm{A}}$ globins. The first and second introns from the $\alpha^{\mathrm{D}}$ globin and the $\beta$ globin were similarly aligned. Phylogenetic and molecular evolutionary analyses were conducted using the Maximum Likelihood statistical method of MEGA version 5.1017).

\section{Results}

Intron nucleotide sequences of $\alpha^{\mathrm{A}}, \alpha^{\mathrm{D}}$, and $\beta$ globins

Fig. 1 shows the strategy for analyzing the intron nucleotide sequences of globin genes from each of the three Geochelone species. The degenerate primers, which were deduced from exon nucleotide sequences of globin genes ${ }^{6,7)}$, are listed in Table 1 . To obtain the complete nucleotide sequences of the second intron of the $\beta$ globin (approximately 1600 base pairs), one or two nested PCR procedures using the nested primers listed in Table 1 were needed. The author established all nucleotide sequences of the first and second introns from each of the three Geochelone species. The full nucleotide sequences (Figs. S1, S2, and S3 in the Supplementary Figures), which were double-checked by forward and reverse cycle sequencing, have been deposited in gene banks under the DDBJ accession numbers listed in Table 2.

\section{Gene tree and divergence time}

Figs. 2A, 2B, and 2C, respectively show the molecular trees (gene trees) of the three Geochelone species revealed by the original sequence of two introns and three exons, three exons aligned as the translational unit of genes, and amino acid sequences derived from the exon nucleotide sequences. The genetic relationships of the three Geochelone species resulted in different branching patterns, indicating they are mutual relationships. Fig. 3 shows a genetic relationship of only introns of the three Geochelone species tested and constructed by the ML statistical method ${ }^{17)}$ whose accuracy of both the topology and branch length were tested and confirmed by several statistical methods as stored in MEGA such as Maximum-Evolutionary,
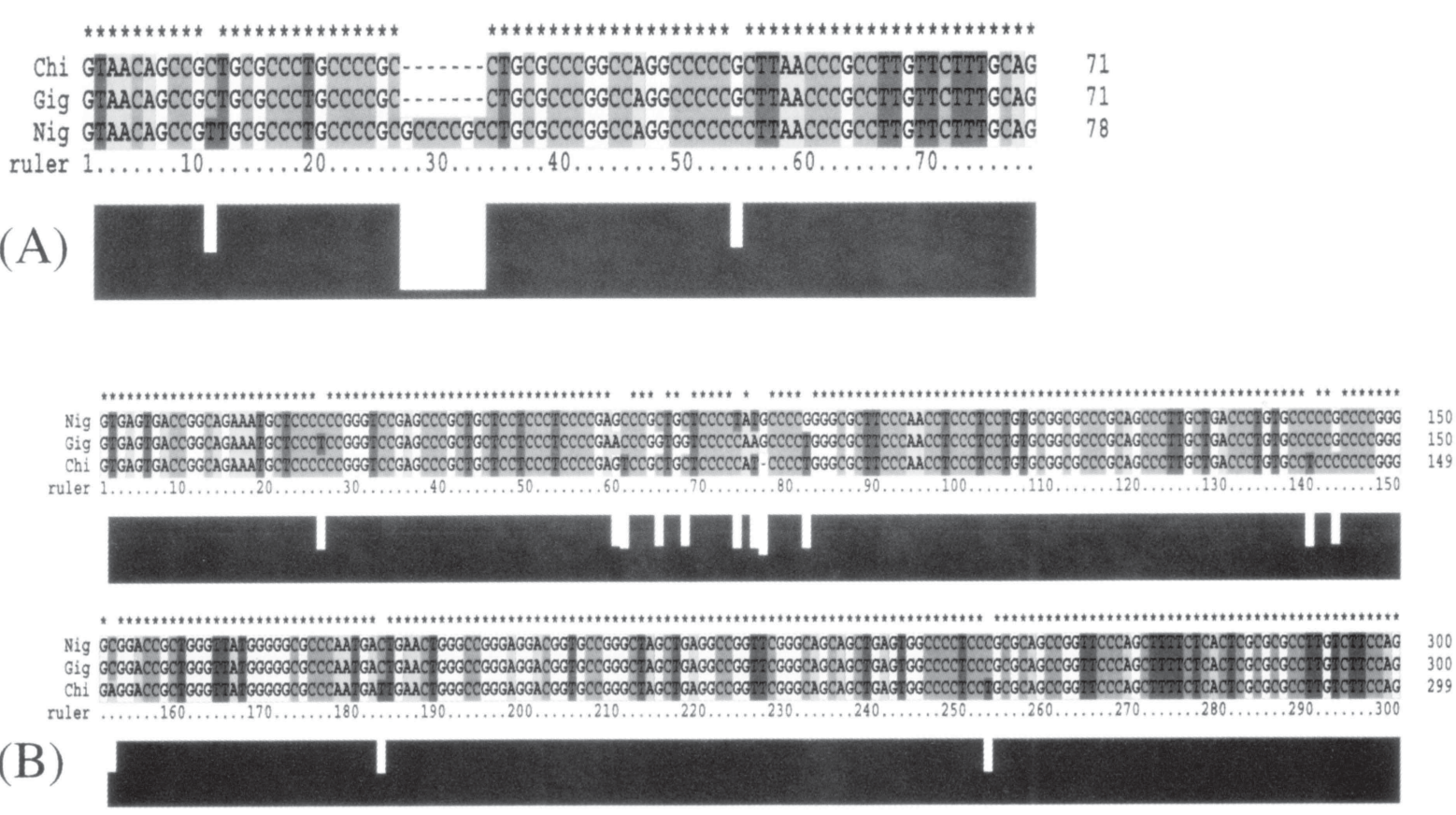

Fig. S1 Alignment of the intron structures of $\alpha^{\mathrm{A}}$ globin. (A); $1^{\text {st }}$ introns of the three species. (B); $2^{\text {nd }}$ introns of the three species. Asterisks indicate invariant nucleotides. Dashed lines are gaps automatically inserted to maximize sequence alignment. Gig: G. gigantea, Nig: G. nigra, Chi: G. chilensis. 

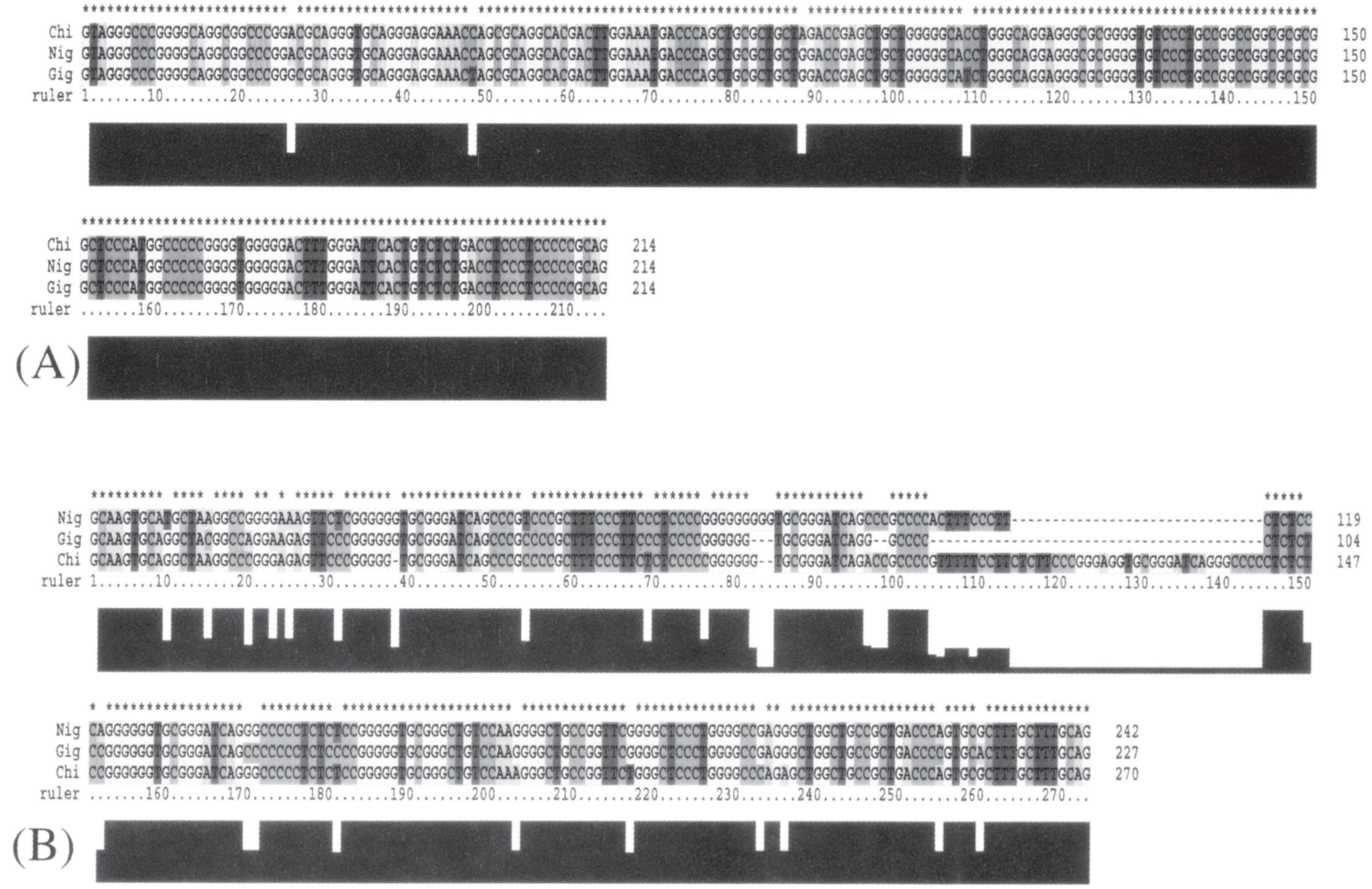

Fig. S2 Alignment of the intron structures of $\alpha^{\mathrm{D}}$ globin. (A); $1^{\text {st }}$ introns of the three species. (B); $2^{\text {nd }}$ intons of the three species. Refer to Fig. S1 for explanations of asterisks, dashed lines, gaps, and abbreviation of species names.

Neighbor-Joining, UPGMA, and Maximum Parsimony ${ }^{17}$.

Goodman et al ${ }^{10)}$ and Czelusniak et al ${ }^{11)}$ measured the separation time of $\beta-\alpha$ globin lineages of gnathostome and amniote (reptile-bird-mammal) ancestors to be about 300-425 mya (average time: 362.5 mya). They also estimated teleost-tetrapod to amniote $\alpha$ globin ancestor and tetrapod to aminote $\beta$ ancestor to be 300-400 mya and 300-340 mya, respectively. Based on this assumption, the divergence times of the three Geochelone species were calculated to be approximately 12-20 mya (Figs. 2A and 2B, Table 3).

\section{GC splicing donor site}

Interestingly, an abnormal GC dinucleotide sequence at the 5 ' splicing donor site not beginning with a consensus GT sequence was detected in the second intron of $\alpha^{\mathrm{D}}$ globin from each of the three Geochelone species (Fig. S2). Together with the previous finding in . $_{\text {. }}$ igantea $^{6}$, this finding is the second instance of abnormal splicing sites (donor/acceptor; 5'-GC/AG-3') in reptiles.

\section{Discussion}

\section{Molecular relationships and divergence times}

Based on mtDNA sequences, Caccone et al ${ }^{14,18)}$ reported two divergence times for the South American tortoises and the Madagascan tortoises: one was 6-12 mya for G. nigra and G. chilensis, and the other was 14-22 mya for the four tortoises endemic to Madagascar (including two species of Geochelone). On the contrary, the author has established the molecular phylogeny of the three populations of Geochelone (one from Africa and two from South America) based on the primary structures of 53 subunits of amniote globins, including those of seven species of reptiles, three species of birds, and humans ${ }^{7}$. The divergence time of the Galapagos giant tortoises and the Aldabra giant tortoises was estimated to be 15-21 mya on the basis of globin genealogy ${ }^{5-7)}$. Even though their present habitats are separated by great distance, it was shown that both giant tortoise species diverged during the early Oligocene to the late Miocene epochs, which is supported by recent studies of the two groups ${ }^{19,20)}$. To reexamine this, the author analyzed the genetic information provided by other components of the globin genes of $\alpha^{\mathrm{A}}, \alpha^{\mathrm{D}}$, and $\beta$, namely introns ${ }^{21)}$. In this report, the author added the results of analysis of globin introns of a key tortoise, the Chaco tortoises.

Despite incorporating additional genetic information, the author was unable to determine which of the species is the ancestral species due to their close relationships: Analysis of the amino acid sequences (Fig. 2C) which was translated from exon nucleotide sequences resulted in good agreement with findings of a previous paper ${ }^{14)}$, however, together with other rela- 


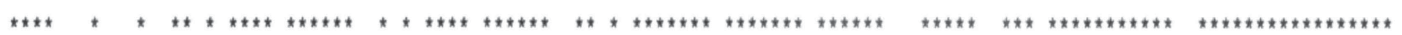

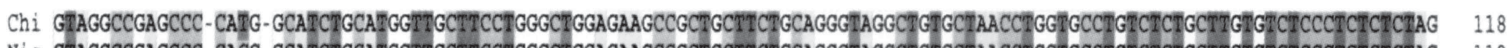

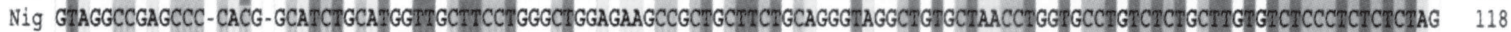

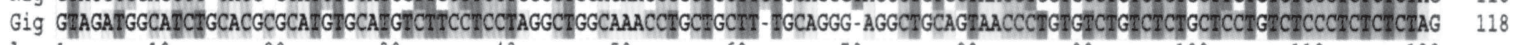

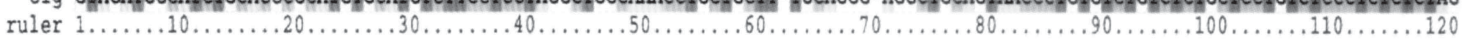

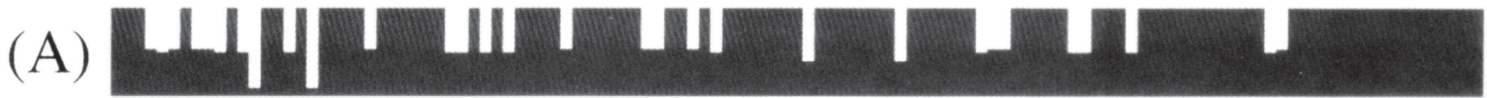

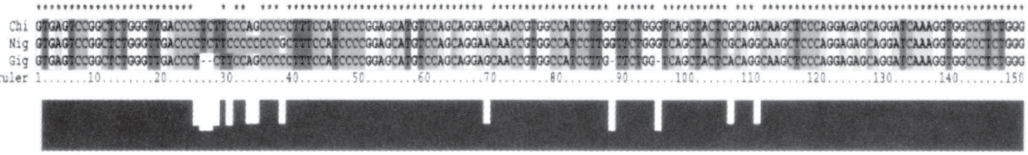

(1)...................................................................................................

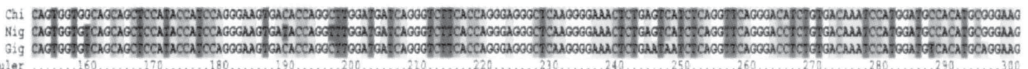

| I I

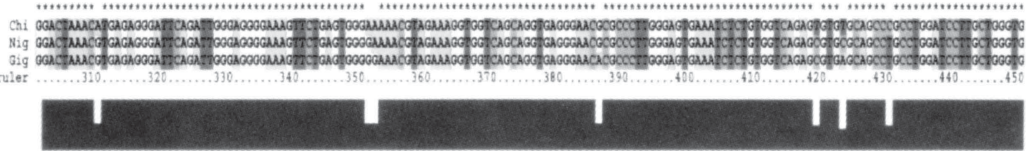

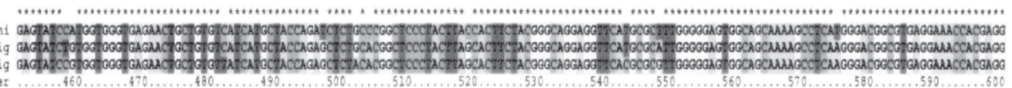

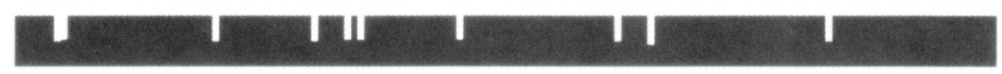

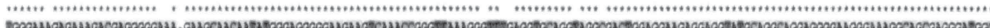

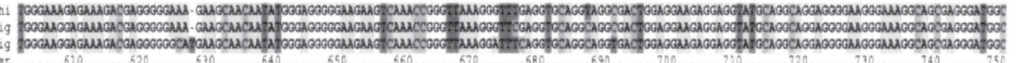
1 110

ni

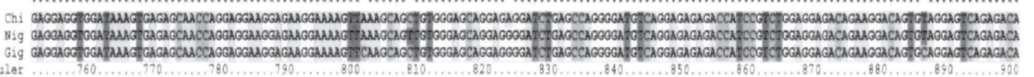
tuler
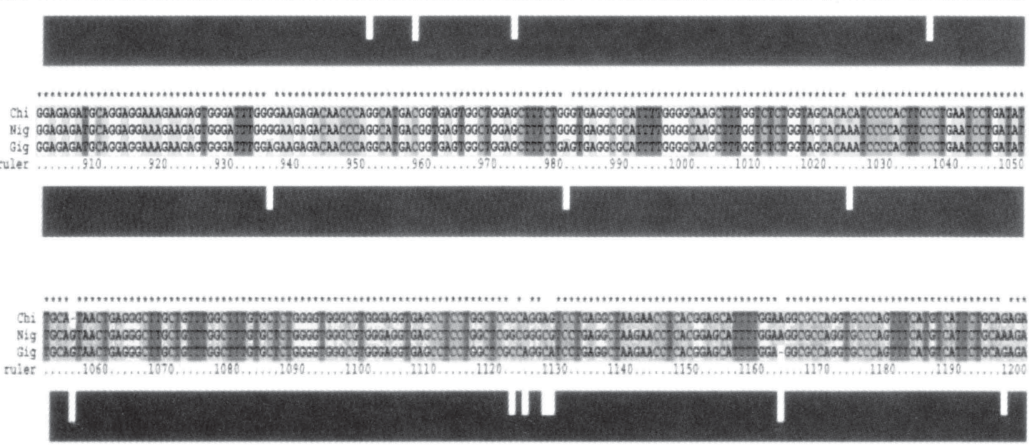

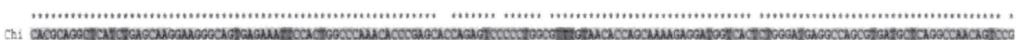

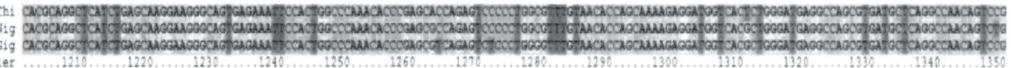
rulet
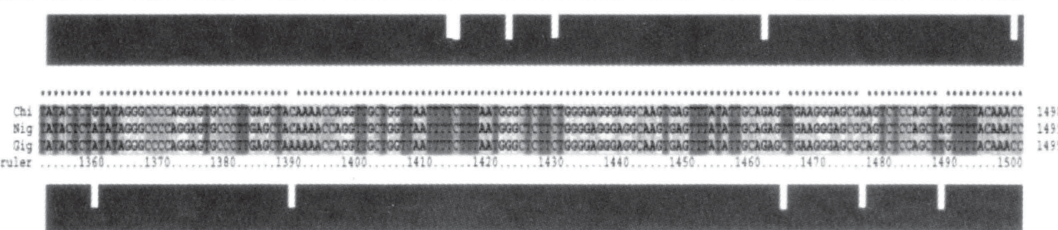

(B)

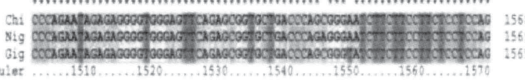

Fig. S3 Alignment of the intron structures of $\beta$ globin. (A); $1^{\text {st }}$ introns of the three species (B); $2^{\text {nd }}$ introns of the three species. Refer to Fig. S1 for explanations of asterisks, dashed lines, gaps, and abbreviation of species names. 
tionships revealed by the complete sequence of the two introns and three exons (Fig. 2A), even only the three exons (Fig. 2B), and intron nucleotide sequences (Fig. 3) showed that they are too closely related to draw a sharp line between the three species.

Recently, the relationship between gene trees and species trees has been the focus of some attention ${ }^{22,23)}$, in which a consensus is that disparities between gene trees and species trees might be related to incomplete lineage sorting ${ }^{23)}$, and gene duplication and $\operatorname{loss}^{24)}$. In this work, it appears that this might be playing a role. However, the author can extract useful information that the two giant tortoises including the small Chaco tortoises separated after the breakup of Gondwana. Table 3 shows that the separation times of the three species occurred approximately 12-20 mya, which supports grossly our previous reports ${ }^{5-7)}$ as well as the mtDNA studies of Caccone et $\mathrm{al}^{14,18)}$.

Table 2 Accession numbers of three kinds of globin genes

\begin{tabular}{lccc}
\hline Species name & $\alpha^{\mathrm{A}}$ globin & $\alpha^{\mathrm{D}}$ globin & $\beta$ globin \\
\hline G.gigantea & $\mathrm{AB} 767267$ & $\mathrm{AB} 072353$ & $\mathrm{AB} 767268$ \\
G.chilensis & $\mathrm{AB} 115330$ & $\mathrm{AB} 115331$ & $\mathrm{AB} 115329$ \\
G. nigra & $\mathrm{AB} 116518$ & $\mathrm{AB} 116521$ & $\mathrm{AB} 116524$ \\
\hline
\end{tabular}

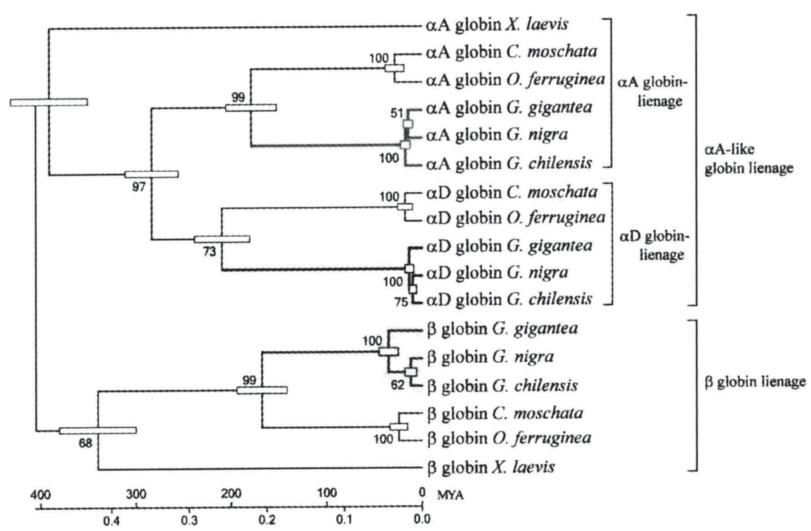

A

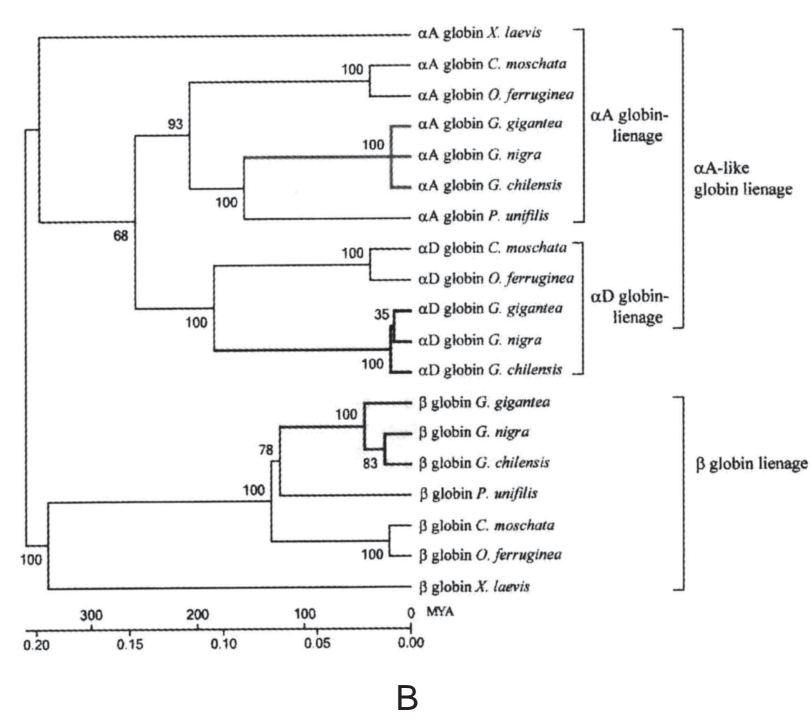

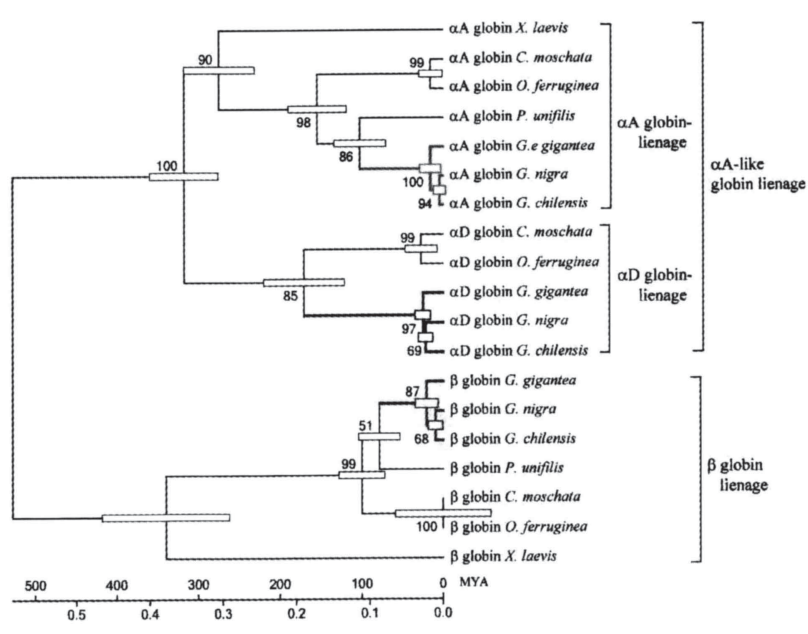

C

Fig. 2 Maximum likelihood (ML) and Neighbor-joining (NJ) trees depicting genetic relationships of the three Geochelone species. (A) The ML tree of the original sequence of two introns and three exons, (B) The NJ tree of the exon sequences (protein coding sequences), and (C) The ML tree of the amino acid sequences. The percentage of replicate trees in which the associated taxa clustered together in the bootstrap test (500 replicates) is shown next to the branches. Evolutionary analyses were conducted the ML method based on the Tamura-Nei mode ${ }^{37)}$ in MEGA5 ${ }^{17)}$. The sequences of the Xenopus laevis $\alpha$ and $\beta$ globin genes were used as out-groups. Refer to Table 2 for accession numbers for globin genes of the three Geochelone species. Other accession numbers used in the present analysis are as follows: X14259; for $\alpha^{\mathrm{A}}$ globin of Xenopus laevis, J00978; for $\beta$ globin of Xenopus laevis, J00923; for $\alpha^{\mathrm{A}}$ globin of Cairina moschata, X01831; for $\alpha^{\mathrm{D}}$ globin of Cairina moschata, X15739; for $\beta$ globin of Cairina moschata, JX911158; for $\alpha^{\mathrm{A}}$ globin of Oxyura ferruginea, JX911204; for $\alpha^{\mathrm{D}}$ globin of Oxyura ferruginea, JX911230; for $\beta$ globin of Oxyura ferruginea, AB605253; for $\alpha^{\mathrm{A}}$ globin of Podocnemis unifilis, AB605254; for $\beta$ globin of Podocnemis unifilis. 


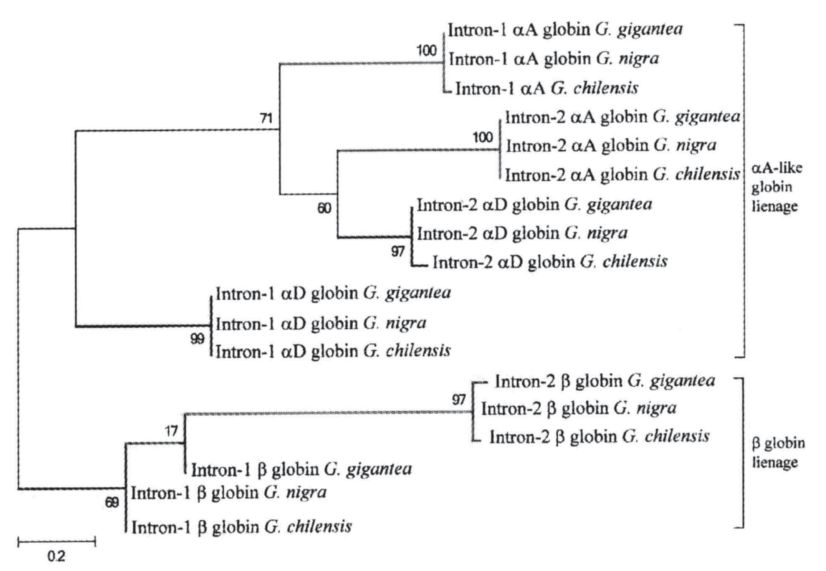

Fig. 3 Maximum likelihood (ML) tree depicting genetic relationships of the three Geochelone species based on intron nucleotide sequences of $\alpha^{\mathrm{A}}, \alpha^{\mathrm{D}}$, and $\beta$ globin genes. Refer to Table 2 for accession numbers for globin genes of the three Geochelone species.

Table 3 Divergence times of three Geochelone species estimated by globin genealogy

\begin{tabular}{|c|c|c|}
\hline \multirow[b]{2}{*}{ Species Name } & \multicolumn{2}{|c|}{$\alpha^{\mathrm{A}}$ globin } \\
\hline & G. gigantea & G. nigra \\
\hline G. gigantea & mya & mya \\
\hline G. nigra & $13.1+/-4.54(17.7)$ & \\
\hline \multirow[t]{2}{*}{ G. chilensis } & $13.1+/-4.54$ (17.7) & $9.71+/-3.92(17.7)$ \\
\hline & \multicolumn{2}{|c|}{$\alpha^{\mathrm{D}}$ globin } \\
\hline Species Name & G. gigantea & G. nigra \\
\hline G. gigantea & mya & mya \\
\hline G. nigra & $14.2+/-4.83(15.5)$ & \\
\hline \multirow[t]{2}{*}{ G. chilensis } & $17.1+/-5.08$ (18.8) & $17.1+/-5.08(18.8)$ \\
\hline & \multicolumn{2}{|c|}{$\beta$ globin } \\
\hline Species Name & G. gigantea & G. nigra \\
\hline G. gigantea & mya & mya \\
\hline G. nigra & $34.2+/-10.06(43.2)$ & \\
\hline G. chilensis & $34.2+/-10.06(43.2)$ & $11.7+/-6.13(24.4)$ \\
\hline
\end{tabular}

Data obtained from Fig. 2A.

Data in parentheses obtained from Fig. 2B.

\section{Migration scenario of the two giant tortoises}

Initially, the giant tortoises of the Indian Ocean and those from the Galapagos were considered to be the same species (referred to as Tortue des Indes, Testudo indica, or Testudo gigantea). In 1834, the Galapagos giant tortoise was classified as a separate species (Testudo nigrita) $^{25)}$, but it still belonged to genus Geochelone (FITZINGER 1835), known to contain "typical tortoises" or "terrestrial turtles". In the 1990s, the subgenus Chelonoidis was proposed and South American members of Geochelone, including the Galapagos giant tortoises (Geochelone nigra) and the Chaco tortoises (Geochelone chilensis) were grouped into an independent clade, Chelonoidis ${ }^{19,20)}$. On the contrary, the Aldabra giant tortoises, Geochelone gigantea (FITZINGER 1835), were also referred to as Dipsochelys dussumieri (GRAY 1831). The author, however, uses genus Geochelone for the three species for the decisive reasons mentioned above.

The break-up of Gondwana, resulting in the opening of the South Atlantic Ocean and the separation of land into two continents, Africa and South America, began at the end of the Jurassic period, 135 mya, and ended at the end of the Cretaceous period, 65 mya $^{9}$. During the early Cretaceous, Madagascar separated from Africa ${ }^{26)}$, and the South Atlantic widened rapidly into a major ocean of approximately 1,000 km wide (about one-third of its present width), while Antarctica was still attached to South America and moved south-westward continually at a slow speed ${ }^{9)}$. If the divergence time scaled according to hemoglobin genealogy, as reported in the literature ${ }^{10-12,27)}$, is correct, then where is the origin of G. nigra and G. gigantea?

Günter ${ }^{1)}$ identified and listed the giant tortoises from the Galapagos and the Indian Ocean islands, including the Seychelles and the Mascarene (now extinct). He theorized that all the giant tortoises were descended from a single ancestral population which spread via subsided land bridges. This theory was later disproved by the understanding that the Galapagos, Seychelles, and Mascarene islands are all of recent volcanic or atoll origin and have never been linked by land bridges. However, the author supports his point of view: because there were no land bridges, the common descendants dispersed by transmarine migration ${ }^{28)}$. The author would like to provide the following scenario explaining the divergence time and the migration processes of the three species: After the break-up of Gondwana, the ancestral species of the two giant tortoise species and the South American land tortoise diverged around 12-20 mya (or 15-21 mya ${ }^{7)}$ ) in Africa, and one ancestral population recently colonized the Galapagos Archipelago by transmarine migration through Antarctica to South America before settling in its present habitat after rafting. On the other hand, one of the other populations which evolved into the Aldabra giant tortoise remained in Africa and recently colonized the Aldabra Atoll directly, or via Madagascar. The migration process of each species suggests several settlement times after the emergence of their present islands: the Galapagos Archipelago was formed 5-9 mya ${ }^{2)}$ and the Aldabra Atoll appeared approximately 13,000 years before present ${ }^{3}$. Here the author would like to provide two supporting elements. The first pertains to expansion of old world monkeys from Africa to the new world (South America and Central America) approximately 40 mya $^{29)}$. The 53 species found in the new world (new world monkeys) 
have been demonstrated to be close relatives to the old world monkeys ${ }^{29)}$. Their routes of migration reflect the transmarine migration routes mentioned above. The second pertains to analyzing the primary structures and exon nucleotide sequences (protein coding sequences) of hemoglobin from the side-necked turtle (Podocnemis unifilis) ${ }^{30)}$, in which the divergence time was tentatively measured to be 102-156 mya (according to $\alpha^{\mathrm{A}}$ globin genealogy) and 78-123 mya (according to $\beta$ globin genealogy); both point to the Cretaceous period in which Gondwana had just begun to separate. These findings might be useful for supporting not only the hemoglobin genealogy used in the present study but also the dispersion of ancestral populations of the side-necked turtles to South America via continental drift. The side-necked turtle is a freshwater turtle that exits the water only for basking or egg-laying. They do not survive well in seawater due to their skin being too weak to sustain long periods of salt exposure. The author is currently in the process of obtaining genetic information from globin genes of sidenecked turtles of two Podocneminae species: one from Madagascar (Podocnemis madagascariensis; synonym: Erymnochelys madagascariensis) and the other from the Amazon River (Podocnemis unifilis).

\section{Abnormal sequences at the 5' splice donor site: GC \\ Splicing sites of introns are highly conserved and play important roles during the processing of precursor mRNA into mature mRNA. In general, the nucleotide sequences of both intron sites, 5' GT at a splice donor site and 3' AG at a splice receptor site, are consensus sequences known as the GT/AG rule. The author first found abnormal GC dinucleotide sequences at the 5' splice site of the second intron of G. gigantea $\left.^{6}\right) \alpha^{\mathrm{D}}$ globin gene, and confirmed them without exception in the Geochelone species studied here. Similarly, in birds, the existence of an identical GC abnormal di- nucleotide sequence at the 5' splice site has been re- ported in the second intron of the $\alpha^{\mathrm{D}}$ globin from chicken $^{31)}$ (Gallus gallus) and duck ${ }^{32}$ ) (Cairina mos- chata). Spingola et $\mathrm{al}^{33)}$ and $\mathrm{Wu}$ and $\mathrm{Krainer}^{34)}$ listed abnormal splicing sites, including GC at the 5' splice donor site in different organisms, and the author is planning to research the significance of this finding. However, these molecular findings imply that reptiles and birds have a close relationship.}

\section{A repeated sequence: 5'-GCCCCGCGCCCCGC-3'}

The next interesting finding is repeated nucleotide sequences with rich $\mathrm{C}$-nucleotides which are common in the intron sequences of all globin genes, in particular, a repeat 5'-GCCCCGCGCCCCGC-3' sequence can be found in the first introns of the $\alpha^{\mathrm{A}}$ globins (Fig. $\mathrm{S} 1)$. This is a conspicuous sequence of the G. nigra $\alpha^{\mathrm{A}}$ globin gene, which infers that $G$. gigantea and $G$. chilensis are more closely related than $G$. nigra and $G$. chilensis. This finding may also provide a key sequence for searching and evaluating the closest species to the Galapagos giant tortoises. Finally, it is worthwhile introducing a research group ${ }^{35,36)}$ who has been discussing a single population from an ancestral stock that evolved into the Galapagos giant tortoise. However, this population is thought to be extinct in coastal western South America.

\section{Conclusions}

1. All introns of $\alpha^{\mathrm{A}_{-}}, \alpha^{\mathrm{D}_{-}}$, and $\beta$-globin from the three Geochelone species, G. nigra, G. gigantea, and $G$. chilensis, were sequenced.

2. Molecular relationships of the three Geochelone species were established by intron nucleotide sequences.

3. The two giant tortoises, G. nigra and G. gigantea, diversified 12-20 mya.

4. An abnormal GC at the 5' splicing site of $\alpha^{\mathrm{D}}$ globin is reported, which supports the idea of close relationships between birds and tortoises on a molecular basis.

5. A repeated 5'-GCCCCGCGCCCCGC-3' sequence is a unique sequence for distinguishing $G$. $n i$ gra from other members of Geochelone species.

\section{Acknowledgements}

The author thanks the late Dr. Koichi Sekiguchi, who donated the Galapagos giant tortoise specimen to Ueno Zoological Garden, and also the Osaka Municipal Tennoji Zoo for supplying the Aldabra giant tortoise specimen.

\section{References}

1) Günter A. Description of the living and extinct races of gigantic land-tortoises. Parts I. \& II. Introduction, and the tortoises of the Galapagos Islands. Phil Trans $R$ Soc Lond 1875; 165B: 251-284.

2) Christie DM, Duncan RA, McBirney AR et al. Drowned islands downstream from the Galapagos hotspot imply extended speciation times. Nature 1992; 355: 246-248.

3) Braithwaite CJR, Taylor JD, Kennedy WJ. The evolution of an atoll: The depositional and erosional history of Aldabra. Phil Trans R Soc Lond 1973; 266B: 307-340.

4) Arnold EN. Indian Ocean giant tortoises: their systematics and island adaptations. Phil Trans R Soc Lond 1979; 286B: 127-145.

5) Shishikura F, Takami K. The amino acid sequences of the $\alpha$-and $\beta$-globin chains of hemoglobin from the Aldabra giant tortoises, Geochelone gigantea. Zool Sci 2001; 18: 515-526.

6) Shishikura F. The primary structure of hemoglobin D from the Aldabra giant tortoise, Geochelone gigantea. Zool Sci 2002; 19: 197-206.

7) Shishikura F. Reptilian hemoglobin: Globin evolution of 
the two giant tortoises, Geochelone gigantea and Geochelone nigra [in Japanese with English abstract]. J Nihon Univ Med Ass 2002; 61: 263-276.

8) Wegener A. Die Entstehung der Kontinente und Ozeane, F. Vieweg \& Sohn, Braunschweig, German, 1920.

9) Dietz RS, Holden JC. The breakup of Pangaea. Sci Am 1970; 223: 30-41.

10) Goodman M, Moore GW, Matsuda G. Darwinian evolution in the genealogy of haemoglobin. Nature 1975; 253: 603608 .

11) Czelusniak L, Goodman M, Hewett-Emmett D et al. Phylogenetic origins and adaptive evolution of avian and mammalian haemoglobin genes. Nature 1982; 298: 297-300.

12) Goodman M, Pedwaydon J, Czelusniak J et al. An evolutionary tree for invertebrate globin sequences. $\mathrm{J} \mathrm{Mol} \mathrm{Evol}$ 1988; 27: 236-249.

13) Hardison RC. Evolution of hemoglobin and its genes. Cold Spring Harb Perspect Med 2012; 2: a011627:1-18. Available from: http://perspectivesinmedicine.cshlp.org/

14) Caccone A, Gibbs JP, Ketmaier V et al. Origin and evolutionary relationships of giant Galápagos tortoises. Proc Nat Acad Sci 1999; 96: 13223-13228.

15) Jeanmougin F, Thompson JD, Gouy M et al. Multiple sequence alignment with Clustal X. Trends Biochem Sci 1998; 23: 403-405.

16) Thompson JD, Higgins DG, Gibson TJ. CLUSTAL W: improving the sensitivity of progressive multiple sequence alignment through sequence weighting, position-specific gap penalties and weight matrix choice. Nucl Acids Res 1994; 22: 4673-4680.

17) Tamura K, Peterson D, Peterson N et al. MEGA5: Molecular evolutionary genetics analysis using maximum likelihood, evolutionary distance, and maximum parsimony methods. Mol Biol Evol 2011; 28: 2731-2739.

18) Caccone A, Amato G, Gratry OC et al. A molecular phylogeny of four endangered Madagascar tortoises based on mtDNA sequences. Mol Phylogenet Evol 1999; 12: 1-9.

19) Le M, Raxworthy CJ, McCord WP et al. A molecular phylogeny of tortoises (Testudines: Testudinidae) based on mitochondrial and nuclear genes. Mol Phylogenet Evol 2006; 40: 517-531.

20) Fritz U, Bininda-Emonds ORP. When genes meet nomemclature: Tortoise phylogeny and the shifting generic concepts of Testudo and Geochelone. Zool 2007; 110: 298 307.

21) Cavalier-Smith T. Intron phylogeny: a new hypothesis.
TIG 1991; 7: 145-148.

22) Pamilo P, Nei M. Relationships between gene trees and species trees. Mol Biol Evol 1988; 5: 568-583.

23) Maddison WP, Knowles LL. Inferring phylogeny despite incomplete lineage sorting. Syst Biol 2006; 55: 21-30.

24) Innan $H$, Kondrashov $F$. The evolution of gene duplications: classifying and distinguishing between models. $\mathrm{Na}$ ture Rev Genet 2010; 11: 97-108.

25) Duméril AMC, Bibron G, Duméril A. Erpétologie générale ou histoire naturelle compléte des reptiles, Librarie Encyclopédique de Roret, 1834. Available from: http://www. archive.org/details/erptologiegnra100bibr goog/

26) Rabinowitz PD, Coffin MF, Falvey D. The separation of Madagascar and Africa. Science 1983; 220: 67-69.

27) Wilson AC, Carlson SS, White TJ. Biochemical evolution. Ann Rev Biochem 1977; 46: 573-639.

28) van Denburgh J. The gigantic land tortoises on the Galapagos archipelago. Proc Calif Acad Sci 1914; 2: 203-374.

29) Ciochon RL, Chiarelli AB. Evolutionary biology of the New World monkeys and continental drift. Plenum Press, New York, 1980

30) Hasegawa T, Shishikura F, Kuwada T. Side-necked turtle (Pleurodira, Chelonia, Reptilia) hemoglobin: cDNA-derived primary structures and X-ray crystal structures of $\mathrm{Hb}$ A. IUBMB Life 2011; 63: 188-196.

31) Dodgson JB, Engel JD. The nucleotide sequence of the adult chicken $\alpha$-globin genes. J Biol Chem 1983; 258: 4623-4629.

32) Erbil C, Niessing J. The primary structure of the duck $\alpha^{\mathrm{D}_{-}}$ globin gene: an unusual 5' splice junction sequence. $E M B O$ J 1983; 2: 1339-1343.

33) Spingola M, Grate L, Haussler DM et al. Genome-wide bioinformatic and molecular analysis of introns in Saccharomyces cerevisiae. RNA 1999; 5: 221-234.

34) Wu Q, Krainer AR. AT-AC pre-mRNA splicing mechanisms and conservation of minor introns in voltage-gated ion channel genes. Mol Cell Biol 1999; 19: 3225-3236.

35) Marlow RW, Patton JL. Biochemical relationships of the Galápagos giant tortoises (Geochelone elephantopus). J Zool Lond 1981; 195: 413-422.

36) Patton JL. Genetical processes in the Galapagos. Biol J Linnean Soc 1984; 21: 97-111.

37) Tamura K, Nei M. Estimation of the number of nucleotide substitutions in the control region of mitochondrial DNA in humans and chimpanzees. Mol Biol Evol 1993; 10: 512 526. 